\title{
Wild blueberries attenuate risk factors of the metabolic syndrome
}

\author{
Dorothy Klimis-Zacas ${ }^{\mathrm{a}, *}$, Stefano Vendrame ${ }^{\mathrm{a}}$ and Aleksandra S. Kristo ${ }^{\mathrm{b}}$ \\ ${ }^{\text {a } U n i v e r s i t y ~ o f ~ M a i n e, ~ O r o n o, ~ M E, ~ U S A ~}$ \\ ${ }^{\mathrm{b}}$ Istanbul Yeni Yuzyil University, Istanbul, Turkey
}

Received 1 February 2016; accepted 11 April 2016

\begin{abstract}
The ability of a wild blueberry-enriched diet to improve risk factors related to Metabolic Syndrome (MetS) such as endothelial dysfunction and chronic inflammation in the Obese Zucker Rat (OZR), a model of the MetS, was studied.

Obese Zucker Rats (OZRs) and their lean controls (LZR) were placed either on a Wild Blueberry-enriched (WB) or a control (C) diet for 8 weeks. Obese Zucker rats exhibited reduced vasoconstrictor response to phenylephrine (Phe) and exaggerated vasorelaxant response to acetylcholine (Ach). WB diet partially restored Phe-induced constrictor responses and attenuated Ach-induced relaxant responses in OZR. Plasma nitric oxide (NO) was significantly attenuated and aortic effluent prostaglandin $\mathrm{I}_{2} \mathrm{PGI}_{2}$ concentration significantly increased in the WB diet. Downregulation of inducible NO synthase (iNOS) and cyclooxygenase-2 (COX-2) expression in the OZR aorta was observed in the WB diet.

WB consumption decreased plasma concentrations of tumor necrosis factor (TNF)- $\alpha(-25.6 \%, P<0.05)$, interleukin (IL)-6 $(-14.9 \%, P<0.05)$, C-reactive protein (CRP) $(-13.1 \%, P<0.05)$ and increased adiponectin concentration $(+21.8 \%$, $P<0.05)$. Expression of IL-6, TNF- $\alpha$ and nuclear factor (NF)-kB was downregulated in both the liver $(-65 \%,-59 \%$ and $-25 \%$, respectively) and the abdominal adipose tissue $(-64 \%,-52 \%$ and $-65 \%)$, while CRP expression was down regulated only in the liver $(-25 \%)$. Thus, WB consumption improved endothelial function and exerted an anti-inflammatory effect in the OZR.
\end{abstract}

Keywords: Metabolic syndrome, inflammation, vascular function, blueberries

\section{Background}

The metabolic syndrome is the most widely recognized association of risk factors leading to a dramatically increased risk of developing type II diabetes mellitus and coronary heart disease (CHD), which continues to be the leading cause of death both in the United States and worldwide [1].

The US National Cholesterol Education Program - Adult Treatment Panel III (ATPIII) defined metabolic syndrome as the combined occurrence of at least three of the following five risk factors: Abdominal obesity, high blood triglycerides, low HDL cholesterol, high blood pressure, and high fasting blood glucose [2]. In addition to these diagnostic criteria, the metabolic syndrome is also associated with endothelial dysfunction, a pro-inflammatory, pro-oxidative and pro-thrombotic environment [3, 4].

Several lines of evidence suggest that diet is one of the most manageable ways of preventing the development of metabolic syndrome, as well as slowing down or even reversing its progression to diabetes and acute

\footnotetext{
${ }^{*}$ Corresponding author: Dorothy Klimis-Zacas, PhD, FACN, Rm 232 Hitchner Hall, School of Food and Agriculture, University of Maine, Orono, ME 04469, USA. Tel.: +1 207581 3124; Fax: +1 207581 1636; E-mail: dorothy.klimis@umit.maine.edu.
} 
cardiovascular events in patients who are already diagnosed with this condition [5, 6]. Even more importantly, dietary interventions in these patients could replace or at least greatly reduce the need for pharmacological treatment, which is inevitably associated with harmful side effects and constitutes a considerable financial burden $[5,6]$.

Wild blueberries are among the commercially available fruits and vegetables that contain the highest levels of polyphenols. They are excellent sources of anthocyanins, but also contain significant amounts of phenolic acids, flavonols and flavan-3-ols as well as manganese, folic acid and vitamin C. Previous research suggests that regular consumption of dietary achievable amounts of this product may have a great potential in the prevention and treatment of risk factors associated with metabolic syndrome [7]. Dietary interventions on human subjects with risk factors for metabolic syndrome have reported some positive outcomes following blueberry consumption, in particular on blood pressure [8,9], oxidative stress [8, 10], insulin sensitivity [11], and endothelial function [9, 12].

\section{Objective}

The objectives of this study are to evaluate the effect of wild blueberry consumption on selected markers of inflammation [13] and endothelial function [14] in the obese Zucker rat (OZR), which is a valid experimental model for the Metabolic Syndrome. Specifically, the effects of an $8 \%$ wild blueberry-enriched diet are measured on plasma markers of inflammation (C-reactive protein (CRP), interleukin(IL)-6, tumor necrosis factor(TNF)- $\alpha$, nitric oxide (NO) and adiponectin); the concentration of prostanoids: $\mathrm{I}_{2}\left(\mathrm{PGI}_{2}\right)$ and thromboxane $\mathrm{A}_{2}\left(\mathrm{TXA}_{2}\right)$ released by the aortic tissue; the expression of genes related to the inflammatory response (IL-6, TNF- $\alpha$, CRP, adiponectin, nuclear factor $(\mathrm{Nf})-\mathrm{kB}$ ) in the liver and the abdominal adipose tissue; the expression of genes related to endothelial function [nitric oxide synthases and cyclooxygenase(COX)-2] in the aortic tissue; and the ex vivo response of the aortic vessel to vasoconstricting and vasorelaxing stimuli.

\section{Methods}

\subsection{Zucker rats}

Thirty-six male obese Zucker rats (OZR) and 36 male lean littermate controls (LZR) were purchased at 8 weeks of age from Charles River laboratories (Raleigh, North Carolina) and housed individually in mesh-bottomed cages in an environmentally controlled room.

Half of the rats were randomly assigned to a wild blueberry-enriched diet (WB) for 8 weeks, while the remaining animals were placed on a control diet $(\mathrm{C})$. The experimental protocol was reviewed and approved by the University of Maine Institutional Animal Care and Use Committee (IACUC).

\subsection{Wild blueberries}

Wild blueberries were provided from Wyman's (Cherryfield, ME) as a composite from different wild blueberry fields in the North Eastern U.S. and Canada. The berries were freeze-dried, powdered and vacuum-packed with standard procedures by FutureCeuticals (Momence, IL), and stored in the dark at $-20^{\circ} \mathrm{C}$ until use.

Analysis of the wild blueberry powder has been previously reported [15], and revealed the presence of twentyone different anthocyanins: Malvidin(Mv)-galactoside (gal) $13.2 \%$ of total ACN; peonidin (Pn)-glucoside (glc) 13.2\%; delphinidin (Dp)-gal 7.8\%; acetyl-Mv-glc 7.2\%; petunidin (Pt)-glc 6.6\%; Pn-arabinoside (ara) 6.0\%; Dp-ara 5.4\%; Pt-gal 4.8\%; cyanidin (Cy)-glc 3.6\%; Cy-gal 3.6\%; Pt-ara 3.0\%; Mv-glc 2.4\%; acetyl-Cy-glc 2.4\%; acetyl-Pt-glc 2.4\%; acetyl-Pn-glc 2.4\%; Cy-ara 1.8\%; Pn-gal 1.8\%; acetyl-Mv-gal 1.8\%; acetyl-Dp-glc $1.2 \%$; Mv-ara $0.6 \%$. 
Total anthocyanin content of the wild blueberry powder was $1.5 \% \mathrm{w} / \mathrm{w}$. Total fiber content was $18 \% \mathrm{w} / \mathrm{w}$ ( $15.2 \%$ insoluble and $2.8 \%$ soluble). Total sugar content was $68.4 \% \mathrm{w} / \mathrm{w}$ (35.2\% glucose and $33.2 \%$ fructose).

\subsection{Diets}

The control diet (AIN-93M) was prepared mixing $691 \mathrm{~g} / \mathrm{kg}$ dextrose, $200 \mathrm{~g} / \mathrm{kg}$ egg white solids, $60 \mathrm{~g} / \mathrm{kg}$ corn oil, $35 \mathrm{~g} / \mathrm{kg}$ mineral mix, $10 \mathrm{~g} / \mathrm{kg}$ vitamin mix (AIN-93), $4 \mathrm{~g} / \mathrm{kg}$ D-L-methionine and $2 \mathrm{mg} / \mathrm{kg}$ biotin. It provided approximately $71 \%$ carbohydrate, $6 \%$ fat, $17 \%$ protein and $403 \mathrm{kcal} / 100 \mathrm{~g}$. The wild blueberry diet was prepared mixing the same ingredients in the same proportions, the only exception being the incorporation of $80 \mathrm{~g} / \mathrm{kg}$ (8\%) wild blueberry powder substituting for an equivalent amount of dextrose. It provided approximately $68 \%$ carbohydrate, $6 \%$ fat, $17 \%$ protein, $1.5 \%$ fiber, $0.12 \%$ anthocyanin and $393 \mathrm{kcal} / 100 \mathrm{~g}$.

Using the body surface area calculation [16] the amount of WB provided to rats corresponds to approximately two daily cups of fresh WB for an average human adult.

\subsection{Sample collection}

At the end of the experimental period, animals were fasted overnight, anesthetized with $95 \% \mathrm{CO}_{2} / 5 \% \mathrm{O}_{2}$ for ninety seconds, and quickly exsanguinated by intra-cardiac puncture. Blood of rats was collected in a tube with $200 \mu \mathrm{L}$ of a 5\% EDTA and immediately processed for plasma separation and storage at $-80^{\circ} \mathrm{C}$ for subsequent analysis. Liver and abdominal adipose tissues were excised, immediately snap-frozen in liquid nitrogen and stored at $-80^{\circ} \mathrm{C}$ for subsequent mRNA extraction.

The thoracic aorta was excised and carefully cleaned to remove blood clots and the perivascular tissues surrounding the vessel. The middle part of the aorta was cut into four rings of approximately $3 \mathrm{~mm}$ length, and immediately used for the evaluation of vasoconstrictor and vasorelaxant responses, as described later.

Another $1 \mathrm{~cm}$ long section from the abdominal end of the aorta was incubated in a $2 \mathrm{~mL}$ Radnoti tissue bath (Radnoti Glass Technology Inc., Monrovia, CA) containing PSS at $37^{\circ} \mathrm{C}$ and aerated with $95 \% \mathrm{O}_{2} / 5 \%$ $\mathrm{CO}_{2}$. Tissue was allowed to equilibrate for $20 \mathrm{~min}$ before adding phenylephrine $\left(10^{-6} \mathrm{M}\right.$ for $\left.10 \mathrm{~min}\right)$ followed by acetylcholine $\left(10^{-5} \mathrm{M}\right.$ for $\left.10 \mathrm{~min}\right)$. The aortic effluent was collected and stored at $-80^{\circ} \mathrm{C}$ for subsequent analysis. The remaining portion of aorta was immediately snap-frozen in liquid nitrogen and stored at $-80^{\circ} \mathrm{C}$ for subsequent mRNA separation.

\subsection{Plasma interleukin-6, $T N F-\alpha$, adiponectin and $C$-reactive protein}

Plasma interleukin-6, TNF- $\alpha$ and adiponectin concentrations were measured using commercially available immunoassay kits (Quantikine Rat IL-6 Immunoassay kit, R\&D Systems \#R6000B; Quantikine Rat TNF$\alpha$ Immunoassay kit, R\&D Systems \#RTA00; Rat Adiponectin ELISA Kit, EMD Millipore \#EZRADP-62K) employing solid-phase enzyme-linked immunosorbent (ELISA) assays. Plasma C-reactive protein (CRP) was measured using the high-sensitivity Rat CRP Elisa Kit (EMD Millipore \#CYT294), which employs a double polyclonal antibody sandwich enzyme immunoassay (EIA). Enzyme activity for all assays was measured spectrophotometrically at $\lambda=450 \mathrm{~nm}$ on a $\mathrm{XMark}^{\mathrm{TM}}$ Microplate Absorbance Spectrophotometer (BioRad, California).

\subsection{Plasma nitric oxide (NO)}

Nitric oxide metabolites in plasma were measured using the colorimetric Total Nitric Oxide and Nitrate/Nitrite Parameter Assay Kit (RandD Systems \#KGE001). The enzyme activity was measured spectrophotometrically at $\lambda=540 \mathrm{~nm}$ on a $\mathrm{xMark}^{\mathrm{TM}}$ Microplate Absorbance Spectrophotometer (BioRad, California). 


\subsection{Prostacyclin $I_{2}\left(P G I_{2}\right)$ and Thromboxane $A_{2}\left(T X A_{2}\right)$ in the aortic effluent}

$\mathrm{PGI}_{2}$ levels in the aortic tissue effluent were estimated using the enzyme immunoassay 6-keto PGF ${ }_{1 \alpha}$ EIA Kit (Cayman \#515211). TXA 2 levels in the aortic tissue were estimated using the enzyme immunoassay Thromboxane $B_{2}$ EIA Kit (Cayman \#519031). The enzyme activity was measured spectrophotometrically at $\lambda=420 \mathrm{~nm}$ on a XMark ${ }^{\mathrm{TM}}$ Microplate Absorbance Spectrophotometer (BioRad, California). Results were normalized to the dry weight of the aorta section used to generate the effluent.

\subsection{Gene expression studies}

Messenger RNA from liver, adipose tissue and aorta were isolated and retro-transcribed to cDNA as previously described $[8,9]$. The reverse transcription product was subjected to two step, real time, reverse transcription polymerase chain reaction (RT-PCR) amplification on a quantitative PCR System (Bio-Rad CFX96) using Sybr Green master mix (SSoFast EvaGreen, Bio Rad \#172-5202) and rat-specific primer sequences targeting the following genes of interest: C-reactive protein (Crp, RefSeq NM_017096, Qiagen \#QT00391650); Interleukin 6 (Il6, RefSeq NM_012589, Qiagen \#QT00182896); Tumor necrosis factor $\alpha$ (Tnf, RefSeq NM_012675, Qiagen \#QT00178717); Adiponectin (Adipoq, RefSeq NM_144744, Qiagen \#QT01169343); Nuclear Factor Kappa B (Nfkb1, RefSeq XM_001075876, Qiagen \#QT01577975); Inducible nitric oxide synthase (Nos2 (RefSeq NM_012611, Qiagen \#QT00178325); Endothelial nitric oxide synthase (Nos3 (RefSeq NM_021838, Qiagen \#QT01570618); Cyclooxygenase-2 (Ptgs2 (RefSeq NM_017232, Qiagen \#QT00192934).

For each primer and tissue, the analysis was performed in triplicate with a reaction volume of $20 \mu \mathrm{L}$ per well $(1.5 \mu \mathrm{L}$ reverse transcription product, $10 \mu \mathrm{L}$ Sybr Green Mix, $2 \mu \mathrm{L}$ primers forward+reverse, and $6.5 \mu \mathrm{L}$ RNAse free water). After an enzyme activation step $\left(95^{\circ} \mathrm{C}\right.$ for $\left.30 \mathrm{~s}\right), 45$ amplification cycles were performed (denaturation at $95^{\circ} \mathrm{C}$ for $2 \mathrm{~s}$, annealing/extension at $60^{\circ} \mathrm{C}$ for $5 \mathrm{~s}$ ) followed by a melting curve $\left(75-95^{\circ} \mathrm{C}\right.$ in $0.5^{\circ} \mathrm{C}$ increases, $2 \mathrm{~s}$ per step) to ensure specificity of amplification.

Relative expression of the genes of interest was determined by the $\Delta \Delta \mathrm{Ct}$ method as described by Livak and Schmittgen [17], relative to the housekeeping gene $\beta$-actin (Actb, RefSeq NM_031144, Qiagen \#QT00193473) and expressed as fold-variation compared to LZR on the control diet.

\subsection{Phenylephrine-induced vasoconstriction}

In a sub-set of 40 rats, a phenylephrine dose-response curve was generated using four aortic rings from each animal to evaluate vasoconstrictor responses.

Each ring was suspended between two stainless steel wire triangles and mounted in a Radnoti tissue bath containing physiological salt solution (PSS) at $37^{\circ} \mathrm{C}$ and aerated with $95 \% \mathrm{O}_{2} / 5 \% \mathrm{CO}_{2}$. The upper triangle was connected to a tissue force analyzer (TFA Model 410, Micro-Med Inc., Louisville, KY) to measure the isometric tension $(\mathrm{g})$ developed in the aortic rings during the experiment. The developed force was recorded and analyzed using a personal computer running DMSI-450 software (version 1.01, Micro-Med Inc., Louisville, KY).

After a preload to adjust resting tension to $1.5 \mathrm{~g}$ (set as the baseline for the subsequent experiment) and a preconditioning with one dose of each agonist (acetylcholine $10^{-8} \mathrm{M}$ and phenylephrine $10^{-8} \mathrm{M}$ for 10 minutes) in order to saturate the non-selective receptors, each ring was contracted with six cumulative phenylephrine doses $\left(10^{-8}, 3 \times 10^{-8}, 10^{-7}, 3 \times 10^{-7}, 10^{-6}, 3 \times 10^{-6}\right)$ at 6 minutes intervals, followed by a dose of muscarinic agonist acetylcholine $\left(3 \times 10^{-6}\right)$ to verify endothelial integrity. The maximum force of vessel contraction (Fmax) was determined for each ring as the highest value of each phenylephrine curve and was used to evaluate the effect of treatments on aorta contractility. 


\subsection{Acetylcholine-induced vasodilation}

For the remaining 32 rats, an acetylcholine dose-response curve was generated using four aortic rings from each animal to evaluate vasodilation. Each aortic ring was mounted and preloaded as described above. Following the pre-incubation period, all rings were precontracted with one maximal phenylephrine dose $\left(3 \times 10^{-6} \mathrm{M}\right)$ for 10 minutes, and subsequently exposed to six cumulative acetylcholine doses $\left(10^{-8}, 3 \times 10^{-8}, 10^{-7}, 3 \times 10^{-7}\right.$, $10^{-6}, 3 \times 10^{-6}$ ) at 6 minutes intervals. The relaxant effect to each dose of acetylcholine was expressed as a percentage of vasorelaxation of the maximum phenylephrine-induced precontraction force.

\subsection{Statistical analysis}

Data from biochemical assays and gene expression experiments were analyzed using a two-way analysis of variance (ANOVA), with diet (WB vs. C diets) and animal model (OZR and LZR) as independent factors. Significant main effects (diets and model) as well as the interactions diet $\times$ model were further evaluated by means of the Tukey honestly significant different (HSD) post hoc test. Data from vasoconstriction and vasorelaxation experiments were evaluated using two-way analysis of variance (ANOVA) with Student-NewmanKeuls comparisons on equal numbers of rank-ordered observations. Statistical analysis was performed using $\mathrm{R}$ statistical software version 2.15.1 (R Foundation for Statistical Computing, Vienna, Austria). Results were expressed as mean \pm SEM and considered significant at $P<0.05$.

\section{Results}

\subsection{Plasma markers of inflammation}

A significant effect of the animal model was observed for C-reactive protein (CRP), interleukin-6 (IL-6), tumor necrosis factor (TNF)- $\alpha$ and adiponectin, whose concentrations were all significantly higher in the OZR group compared to the LZR group. Within the OZR group, a significant effect of diet was observed for IL-6, TNF- $\alpha$ and CRP which were significantly lower in the wild blueberry group compared to the control $(-14.9 \%,-25.6 \%$ and $-13.1 \%$ respectively), while adiponectin levels were significantly higher $(+21.8 \%)$. Similar trends were observed within the LZR group, although a statistically significant interaction with wild blueberry diet was only observed for IL-6 (-6.8\%). Plasma NO concentrations were significantly higher in the OZR group compared to the LZR group (+45\%). In OZR, plasma NO concentrations were significantly lower $(-14 \%)$ following wild blueberry consumption. Conversely, in LZR, plasma NO concentrations were significantly higher following wild blueberry consumption $(+16 \%)$ (Table 1$)$.

\subsection{Prostanoid concentrations in the aortic effluent}

No effect of the animal model was observed for prostanoid concentrations $\left(\mathrm{PGI}_{2}\right.$ and $\left.\mathrm{TXA}_{2}\right)$ in the aortic effluent. Following wild blueberry consumption, prostacyclin concentrations in the aortic effluent significantly increased in the OZR group ( $+34 \%)$. Thromboxane $\mathrm{A}_{2}$ levels were unaffected with wild blueberry consumption (Table 1).

\subsection{Expression of the TNF- $\alpha$ gene in the liver and abdominal adipose tissue}

In the liver, expression of TNF- $\alpha$ was significantly lower in the wild blueberry group compared to the control, for both OZR (-59\%) and LZR (-50\%). In the abdominal adipose tissue, expression of TNF- $\alpha$ was significantly lower in the wild blueberry group compared to the control in the OZR group (-52\%) but not in the LZR group. 
Table 1

Fasting plasma levels of inflammatory markers and aortic prostanoids in lean and obese Zucker rats following a control or a wild blueberry diet

\begin{tabular}{lcccc}
\hline & LZR-C & LZR-WB & OZR-C & OZR-WB \\
& $n=10$ & $n=10$ & $n=10$ & $n=10$ \\
\hline $\mathrm{CRP}(\mu \mathrm{g} / \mathrm{mL})$ & $242.0 \pm 35.5$ & $226.0 \pm 27.3$ & $438.5 \pm 44.2^{+}$ & $381.0 \pm 35.2^{*}$ \\
$\mathrm{IL}-6(\mathrm{pg} / \mathrm{mL})$ & $189.4 \pm 7.9$ & $176.6 \pm 6.7$ & $257.7 \pm 7.7^{+}$ & $219.3 \pm 8.0^{*}$ \\
$\mathrm{TNF}-\alpha(\mathrm{pg} / \mathrm{mL})$ & $8.3 \pm 0.4$ & $7.3 \pm 0.5$ & $38.7 \pm 0.9^{+}$ & $28.8 \pm 0.8^{*}$ \\
Adiponectin $(\mu \mathrm{g} / \mathrm{mL})$ & $12.1 \pm 0.9$ & $12.6 \pm 0.9$ & $17.0 \pm 1.1^{+}$ & $20.7 \pm 1.5^{*}$ \\
Plasma NO $(\mu \mathrm{mol} / \mathrm{L})$ & $17.6 \pm 0.6$ & $20.5 \pm 0.7^{*}$ & $25.6 \pm 1.4^{+}$ & $22.1 \pm 1.1^{*}$ \\
6kPGF1 $\alpha(\mathrm{pg} / \mathrm{mg}$ aorta) & $517.7 \pm 60.4$ & $601.5 \pm 65.8$ & $571.7 \pm 37.8$ & $766.5 \pm 92.2^{*}$ \\
TXB2 $(\mathrm{pg} / \mathrm{mg}$ aorta) & $4.24 \pm 0.40$ & $4.35 \pm 0.44$ & $4.42 \pm 0.89$ & $4.16 \pm 0.63$ \\
\hline
\end{tabular}

Values are means \pm SEM. ${ }^{*}$, significant effects of diet $(P<0.05) .+$, significant effect of model $(P<0.05)$. CRP, C-reactive protein; IL, Interleukin; TNF, Tumor Necrosis Factor; NO, Nitric Oxide; 6-keto PGF1 $\alpha$, 6-keto prostaglandin F1; $\mathrm{TXB}_{2}$, Thromboxane $\mathrm{B}_{2}$; LZR, lean Zucker rats; OZR, obese Zucker rats; $\mathrm{C}$, control diet; WB, wild blueberry diet.

Expression of TNF- $\alpha$ both in the liver and the adipose tissue was markedly increased in the OZR on the control diet compared to LZR, and this effect was almost completely reversed by the wild blueberry treatment (Fig. 1).

\subsection{Expression of $N f-k B$ gene in the liver and abdominal adipose tissue}

In the liver, expression of $\mathrm{Nf}-\mathrm{kB}$ was significantly lower in the wild blueberry group compared to the control, for both OZR (-25\%) and LZR (-24\%). In the abdominal adipose tissue, Nf-kB expression was significantly lower in the wild blueberry group compared to the control in the OZR (-65\%) but not in the LZR group. Expression of $\mathrm{Nf}-\mathrm{kB}$ both in the liver and the adipose tissue was markedly increased in the OZR on the control diet compared to their lean controls, and this effect was attenuated by the wild blueberry treatment (Fig. 1).

\subsection{Expression of IL-6 gene in the liver and abdominal adipose tissue}

Liver expression of IL-6 was significantly lower in the wild blueberry group compared to the control, for both OZR $(-65 \%)$ and LZR $(-21 \%)$. In the abdominal adipose tissue, IL-6 expression was significantly lower in the wild blueberry group compared to the control in the OZR group (-64\%) but not in the LZR group. Furthermore, expression of IL- 6 both in the liver and the adipose tissue was markedly increased in the OZR on the control diet compared to their lean controls, and this effect was almost completely reversed by the wild blueberry treatment (Fig. 1).

\subsection{Expression of the CRP gene in the liver}

Liver expression of CRP was on average lower in the OZR compared to the LZR, independent of treatment. Wild blueberry treatment significantly decreased CRP expression in both groups $(-16 \%$ in LZR and $-25 \%$ in OZR) (Fig. 1).

\subsection{Expression of the adiponectin gene in the abdominal adipose tissue}

Expression of adiponectin in the abdominal adipose tissue was significantly higher in the OZR group compared to the LZR, independent of diet. Furthermore, wild blueberry treatment significantly increased adiponectin 


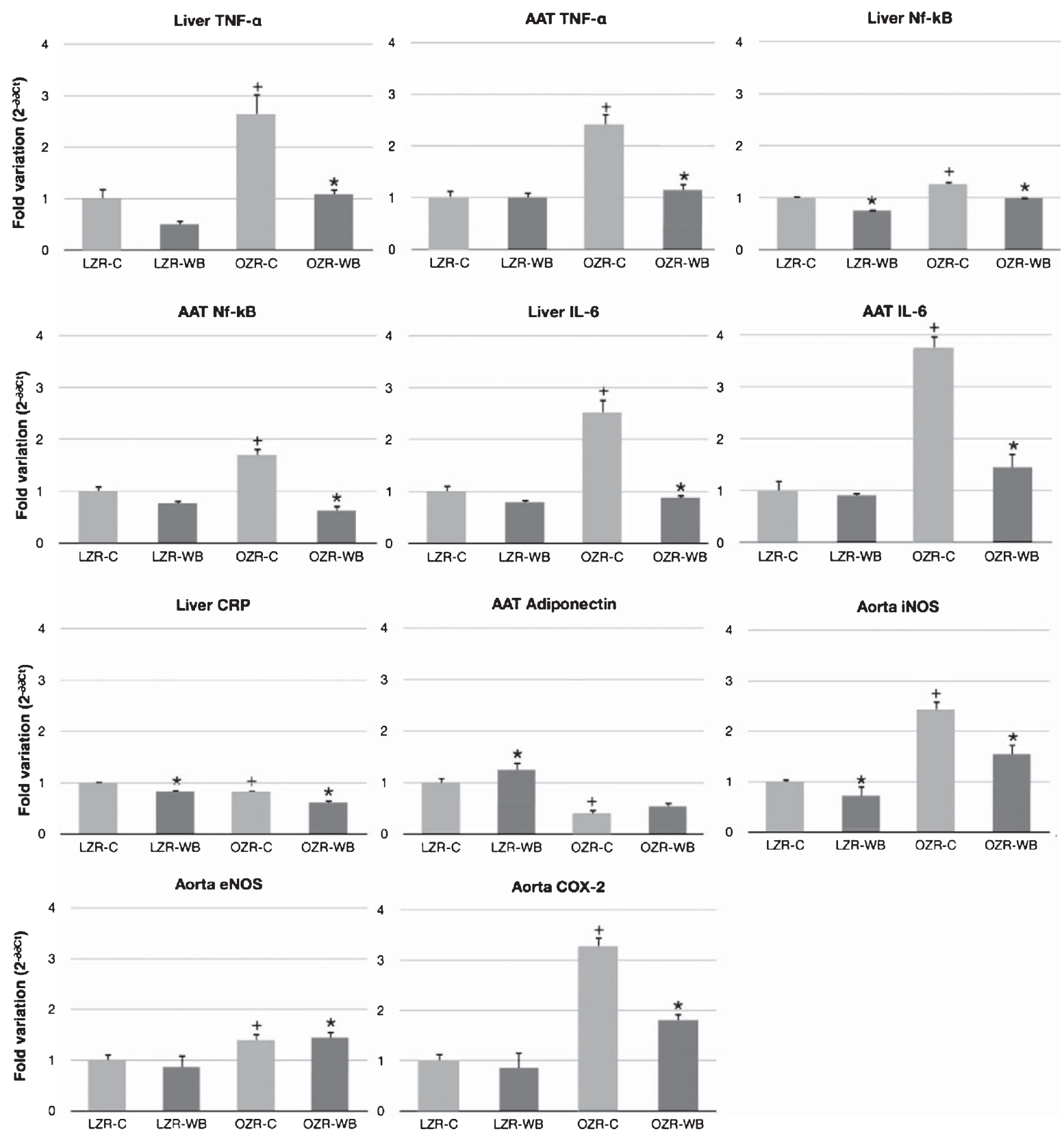

Fig. 1. Relative expression of inducible nitric oxide synthase (iNOS), endothelial nitric oxide synthase (eNOS), cyclooxygenase (COX)-2, tumor necrosis factor (TNF)- $\alpha$, adiponectin, interleukin (IL)-6, C-reactive protein (CRP) and Nuclear factor (Nf)-kB in the aorta, liver and abdominal adipose tussue (AAT) of lean (LZR) and obese (OZR) Zucker rats following a control (C) or a wild blueberry (WB) diet. Values are means \pm SEM, expressed as $2^{-\Delta \Delta C t}$ normalized to $\beta$-actin and relative to LZR-C. $n=10$ for each group. ${ }^{*}$, significant effects of diet $(P<0.05) .+$, significant effect of model $(P<0.05)$. 
expression in LZR (+25\%), but not in OZR. Expression of adiponectin in hepatocytes was too low to generate usable PCR data, and was therefore not considered in the analysis (Fig. 1).

\subsection{Expression of the inducible (iNOS) and endothelial (eNOS) nitric oxide synthase genes in the aorta}

A significant effect of the animal model was observed for mRNA expression of both the eNOS and iNOS genes, which were all higher in the aortic tissues of the OZR compared to LZR. While no interaction with the diet was observed for eNOS, the wild blueberry diet resulted in a significant down-regulation of iNOS expression both in the OZR and LZR aorta (Fig. 1).

\subsection{Expression of the cyclooxygenase 2 (COX-2) gene in the aorta}

A significant effect of the animal model was observed for mRNA expression of the COX-2 gene, which was higher in the aortic tissue of OZR compared to LZR. Following wild blueberry consumption, COX expression was significantly attenuated in the aorta of OZR (Fig. 1).

\subsection{Phenylephrine-induced vasoconstriction and acetylcholine-induced vasorelaxation}

The cumulative dose-response curves to phenylephrine (Phe) induced endothelium-dependent vasoconstriction and to acetylcholine (Ach)-induced endothelium-dependent vasorelaxation are shown in Fig. 2.

Phe-induced vasoconstriction was significantly lower in OZR-C (Fmax $0.43 \pm 0.02 \mathrm{~g}$ ) compared to LZR-C (Fmax $0.74 \pm 0.02 \mathrm{~g}$ ). Wild blueberry feeding partially restored Phe-induced constrictor responses in OZR, with significant increase in the maximal force developed (Fmax $0.55 \pm 0.02 \mathrm{~g}, p<0.05$ ). Constrictor responses in LZR were unaffected by WB in response to all Phe doses.

The maximal relaxation in response to acetylcholine was significantly higher in OZR $(97.62 \pm 1.78 \%)$ compared to LZR $(80.26 \pm 1.66 \%)$. The WB diet did not have any effect in OZR, but resulted in enhanced relaxation in LZR (maximal relaxation $90.73 \pm 1.80 \%$ ).
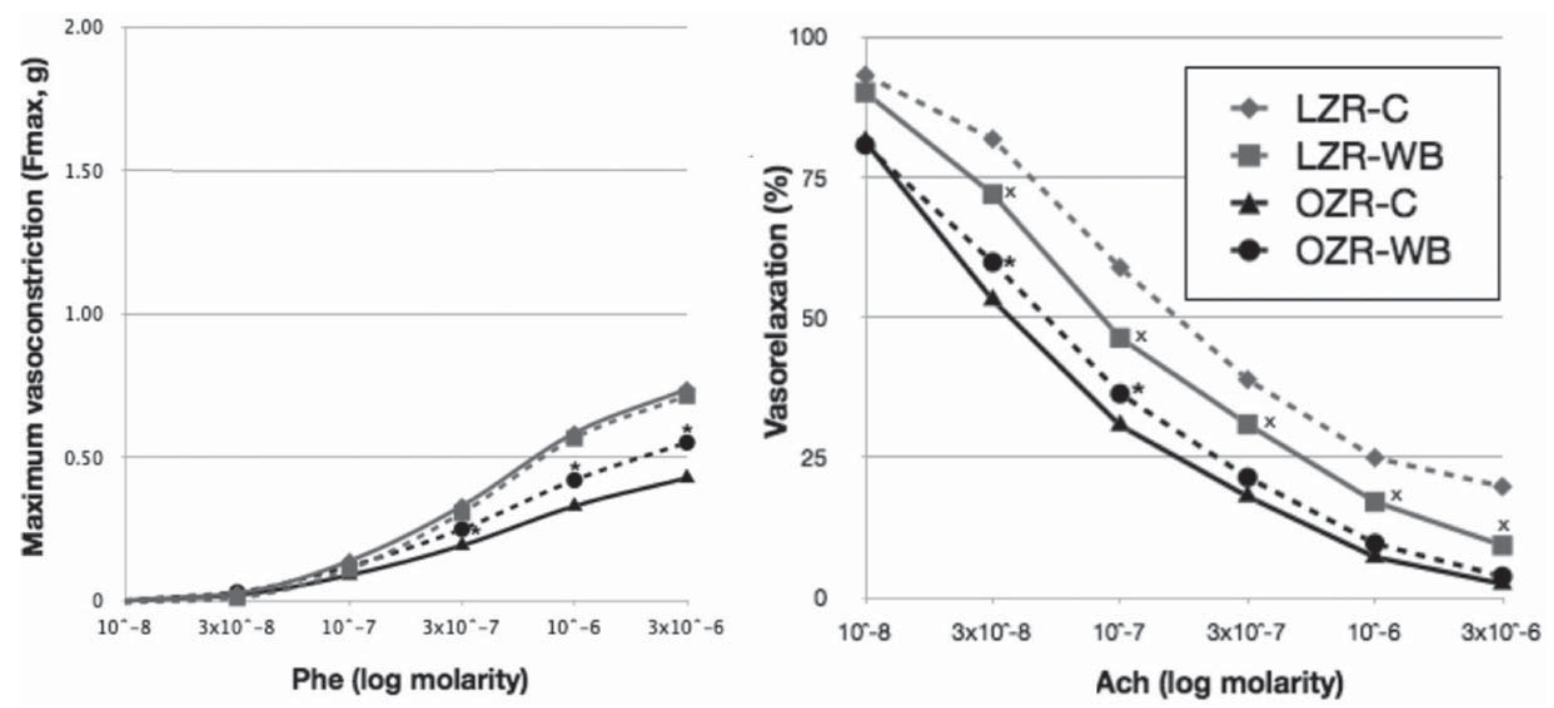

Fig. 2. Phenylephrine (Phe) and acetylcholine (Ach) concentration-response curves in lean (LZR) and obese (OZR) Zucker rats following a control (C) or a wild blueberry (WB) diet. Values are means \pm SEM. ${ }^{*}$, significant effects of diet $(P<0.05)$. 


\section{Conclusions}

The OZR is an excellent experimental model to study the metabolic syndrome because it presents many similarities with the metabolic abnormalities and the natural history of this condition in humans [18]. The alterations in lipid and glucose metabolism in these animals are accompanied by a profound pro-oxidant, prothrombotic and pro-inflammatory state, which results in higher circulating levels of pro-inflammatory cytokines [18]. This fact was confirmed by the present study, in which significantly higher circulating levels of CRP, IL-6 and TNF- $\alpha$, and significantly lower levels of adiponectin, were measured in the OZR group compared to their littermate controls (the LZR group).

Wild blueberry consumption exerted a significant overall anti-inflammatory effect in OZR. Plasma levels and liver expression of CRP were significantly decreased, adiponectin plasma concentrations significantly increased, and plasma levels of IL- 6 and TNF- $\alpha$ were significantly decreased by down-regulating the expression of these pro-inflammatory cytokines in both the liver and the abdominal adipose tissue. In fact, the increased liver and adipose mRNA levels of IL- 6 and TNF- $\alpha$ that were observed in OZR, were almost completely reversed following wild blueberry consumption to levels comparable to those observed in their healthy lean littermates.

These findings are consistent with previous research suggesting that anthocyanins are able to exert important anti-inflammatory effects. Feeding anthocyanin-rich extracts to mice on a high-fat diet resulted in decreased TNF$\alpha$ expression $[19,20]$, and the same outcome was observed in mice adipocytes when $4 \%$ whole blueberry powder was added for 8 weeks to a high-fat diet [21]. In hypercholesterolemic humans, decreased levels of serum CRP were measured in after 24 weeks of consumption of a purified anthocyanin mixture ( $320 \mathrm{mg}$ twice a day) [22].

The most likely mechanism underlying the observed anti-inflammatory effect of anthocyanins and polyphenols involves NF-kB activation [23, 24]. Karlsen and colleagues [25] documented that anthocyanin supplementation inhibited NF-kB and decreased markers of inflammation both in human monocytes and in healthy adults. In this study, mRNA expression of NF-kB was indeed significantly higher in OZR compared to LZR, which could explain the overall pro-inflammatory environment observed in these animals, and wild blueberry treatment decreased NF-kB expression both in the liver and abdominal adipose tissue of OZR. A similar outcome was observed by Seymour and colleagues [26]: $1 \%$ freeze-dried whole tart cherry powder supplementation for 90 days decreased NF-kB activity in OZR fed a high-fat diet, along with IL-6 and TNF- $\alpha$ expression. Activation of inducible nuclear transcription factor NF-kB induced by oxidative stress leads to an up-regulation of pro-inflammatory molecule expression, including TNF- $\alpha$ and IL-6, and possibly a down-regulation of anti-inflammatory molecules, such as adiponectin [27].

Thus, it is safe to speculate that the anti-inflammatory effect observed for wild blueberry bioactives, is largely dependent on the inhibition of NF-kB functional transcription activity, resulting in lower production of proinflammatory cytokines and an increase of anti-inflammatory mediators. Nf-kB has been shown, in vitro and in vivo, to be inhibited by bioactives including $\mathrm{ACNs}$, likely via inhibition of $\mathrm{kB}$ inhibitor kinases [28, 29].

Nf-kB also represents an important link between inflammation and endothelial dysfunction, since several genes which encode key proteins affecting endothelial function, including iNOS and COX-2, are also under its transcriptional control [29].

The present study also examined the effects of a wild blueberry-enriched diet on vasoconstricting and vasorelaxing responses in the OZR aortic vessel, which has been previously reported to show exaggerated endothelium-dependent vasodilator responses and impaired endothelium-dependent vasoconstrictor responses compared to their lean littermate controls [30, 31].

Indeed, in this study, OZR exhibited impaired vasoconstrictor responses to the $\alpha-1$ adrenergic agonist phenylephrine, developing a lower maximal force of contraction compared with LZR, vasorelaxant responses to acetylcholine were found to be significantly higher in the OZR compared with LZR. However, wild blueberry consumption significantly increased the maximal force of contraction in response to phenylephrine in OZR, while not affecting vasoconstrictor responses in LZR. Acetylcholine-mediated vasorelaxation was enhanced in LZR, while the effect of wild blueberry on vasorelaxation in the OZR tended to be in opposite direction. 
A similar response was reported by Andrews and colleagues [32], who observed enhanced vasodilator responses in LZR and reduced vasodilator responses in OZR hindquarter vessel preparations following 4-week supplementation with the antioxidant vitamin E. This suggests that the overcompensated endothelial response of OZR may be the result of a protective adaptation to the increased levels of oxidative stress. A likely explanation for the vascular hypo-responsiveness of OZR to phenylephrine in OZR and their exaggerated vasodilator reactivity to acetylcholine is the up-regulation of the inducible, calcium-independent isoform of nitric oxide synthase, caused in the endothelium and the smooth muscle by pro-inflammatory cytokines, including TNF- $\alpha$ [33]. In turn, iNOS activation results in a pathologic release of nitric oxide, which has been shown in vitro to lead to vascular relaxation that is resistant to vasoconstrictors [33]. The existence of an association between inflammatory conditions and overproduction of nitric oxide has been repeatedly established [34], and it is likely the result of a compensatory adaptation to preserve blood flow in a pro-oxidant, pro-inflammatory, and dyslipidemic environment. Under such conditions, however, most iNOS-derived nitric oxide does not undergo the physiologic conversion to nitrite, and instead it reacts with superoxide anion to generate the highly reactive peroxynitrite radical, which further exacerbates to oxidative stress and endothelial dysfunction [34]. The findings of the present study are consistent with this model: OZR were found to have higher plasma levels of nitric oxide, and a 2.5-fold higher expression of iNOS in the aortic tissue, compared with LZR. Following wild blueberry consumption, nitric oxide concentrations decreased in OZR and aortic iNOS expression was significantly down-regulated. Aortic expression of COX-2, which like iNOS is also under transcriptional control of Nf-kB, was also significantly higher in OZR and down-regulated following wild blueberry diet, although $\mathrm{PGI}_{2}$ and $\mathrm{TXA}_{2}$ in the aortic effluent were not significantly different between OZR and their lean controls. Wild blueberry consumption did not affect $\mathrm{TXA}_{2}$ concentrations in the aortic effluent, possibly because its production is mostly controlled by the constitutive COX-1 isoform. Interestingly, however, $\mathrm{PGI}_{2}$ concentrations increased following wild blueberry in spite of COX-2 downregulation, suggesting a shift in prostanoid production. Indeed, while the contribution of $\mathrm{PGI}_{2}$ to endothelium-dependent relaxation is limited, its effects on inhibition of platelet aggregation are stronger and synergistic with nitric oxide [35]. Hence, the observed increase in prostacyclin may represent a compensatory mechanism in response to the decreased availability of nitric oxide, to preserve anti-thrombotic function [34].

In conclusion, the present study investigated the effects of wild blueberry consumption in the OZR model of metabolic syndrome. In previous studies, we have already documented that wild blueberry consumption is able to improve lipid profile and normalize some dysregulated parameters of glucose metabolism in the OZR $[36,37]$.

In this study, wild blueberry consumption exerted an overall attenuation of the augmented pro-inflammatory environment that is characteristic of OZR. A clear reduction in circulating levels of markers of inflammatory status was observed, as well as their reduced expression levels, both in the adipose tissue and the liver.

Furthermore, wild blueberry consumption affected the aortic biomechanical function of the OZR by partially restoring the impaired phenylephrine-induced constrictor responses, and attenuating the exaggerated response to acetylcholine-induced vasorelaxation.

The documented anti-inflammatory and endothelium-protective effect of medium-term, dietary-achievable wild blueberry consumption on the OZR model may have implications for the human metabolic syndrome, and the possibility of a dietary-based, non-pharmacologic approach in preventing or reversing its related risk factors.

\section{Acknowledgments}

This work was partially supported by the Wild Blueberry Association of North America and by Hatch Grant no. ME0-8553-09 from the United States Department of Agriculture, National Institute of Food and Agriculture. Maine Agricultural and Forest Experiment Station publication number 3475. 


\section{References}

[1] Go AS, Mozaffarian D, Roger VL, Benjamin EJ, Berry JD, Borden WB, et al. Heart disease and stroke statistics-2013 update: A report from the American Heart Association. Circulation. 2013;127(1):e6-e245.

[2] Alberti, KG, Eckel RH, Grundy SM, Zimmet PZ, Cleeman JI, Donato KA, et al. Harmonizing the metabolic syndrome: A joint interim statement of the International Diabetes Federation Task Force on Epidemiology and Prevention; National Heart, Lung, and Blood Institute; American Heart Association; World Heart Federation; International Atherosclerosis Society; and International Association for the Study of Obesity. Circulation. 2009;120:1640-5.

[3] Kaplan NM. The deadly quartet. Upper-body obesity, glucose intolerance, hypertriglyceridemia, and hypertension. Arch Intern Med. 1989;149:1514-20.

[4] Nugent AP. The metabolic syndrome. Nutrition Bulletin. 2004;29:36-43.

[5] Sarti C, Gallagher J. The metabolic syndrome: Prevalence, CHD risk, and treatment. J Diabetes Complications. 2006;20:121-32.

[6] Ervin RB. Prevalence of metabolic syndrome among adults 20 years of age and over, by sex, age, race and ethnicity, and body mass index: United States, 2003-2006. National health statistics reports; no 13. Hyattsville, MD: National Center for Health Statistics. 2009.

[7] Basu A, Lyons TJ. Strawberries, Blueberries and Cranberries in the Metabolic Syndrome: Clinical perspectives. J Agric Food Chem. 2012;60:5687-92.

[8] Basu A, Du M, Leyva MJ, Sanchez K, Betts NM, Wu M, Aston CE, Lyons TJ. Blueberries decrease cardiovascular risk factors in obese men and women with metabolic syndrome. J Nutr. 2010;140:1582-7.

[9] Johnson SA, Figueroa A, Navaei N, Wong A, Kalfon R, Ormsbee LT, Feresin RG, Elam ML, Hooshmand S, Payton ME, Arjmandi BH. Daily blueberry consumption improves blood pressure and arterial stiffness in postmenopausal women with pre- and stage 1-hypertension: A randomized, double-blind, placebo-controlled clinical trial. J Acad Nutr Diet. 2015;115:369-77.

[10] Riso P, Klimis-Zacas D, Del Bo' C, Martini D, Campolo J, Vendrame S, Møller P, Loft S, De Maria R, Porrini M. Effect of a wild blueberry (Vaccinium angustifolium) drink intervention on markers of oxidative stress, inflammation and endothelial function in humans with cardiovascular risk factors. Eur J Nutr. 2013;52:949-61.

[11] Stull AJ, Cash KC, Johnson WD, Champagne CM, Cefalu WT. Bioactives in blueberries improve insulin sensitivity in obese, insulin-resistant men and women. J Nutr. 2010;140:1764-8.

[12] Stull AJ, Cash K, Champagne CM, Gupta AK, Boston R, Beyl RA, Johnson WD, Cefalu WT. Blueberries improve endothelial function, but not blood pressure, in adults with metabolic syndrome: A randomized, double-blind, placebo-controlled clinical trial. Nutrients. 2015;7:4107-23.

[13] Vendrame S, Daugherty A, Kristo AS, Riso P, Klimis-Zacas D. Wild blueberry (Vaccinium angustifolium) consumption improves inflammatory status in the obese Zucker rat model of the metabolic syndrome. J Nutr Biochem. 2013;24:1508-12.

[14] Vendrame S, Kristo AS, Schuschke D, Klimis-Zacas D. Wild blueberry consumption affects aortic vascular function in the obese Zucker rat. Appl Physiol Nutr Metab. 2014;39:255-61.

[15] Del Bo' C, Ciappellano S, Klimis-Zacas D, Martini D, Gardana C, Riso P, Porrini M. Anthocyanin absorption, metabolism, and distribution from a wild blueberry-enriched diet (Vaccinium angustifolium) is affected by diet duration in the Sprague-Dawley rat. $\mathrm{J}$ Agric Food Chem. 2010;58:2491-97.

[16] Reagan-Shaw S, Nihal M, Ahmad N. Dose translation from animal to human studies revisited. FASEB J. 2007;22:659-61.

[17] Livak KJ, Schmittgen TD. Analysis of relative gene expression data using real-time quantitative PCR and the Delta Delta CT method. Methods. 2005;25:402-8.

[18] Tofovic SP, Jackson EK. Rat models of the metabolic syndrome. Methods Mol Med. 2003;86:29-46

[19] Lefevre M, Wiles J, Zhang X, Howard L, Gupta S, Smith A, et al. Gene expression microarray analysis of the effects of grape anthocyanins in mice: A test of a hypothesis-generating paradigm. Metabolism. 2008;57:S52-S57.

[20] Tsuda T, Ueno Y, Aoki H, Koda T, Horio F, Takahashi N, et al. Anthocyanin enhances adipocytokine secretion and adipocyte-specific gene expression in isolated rat adipocytes. Biochem Biophys Res Commun. 2004;316:149-57.

[21] DeFuria J, Bennett G, Strissel KJ, Perfield JW 2nd, Milbury PE, Greenberg AS, Obin MS. Dietary blueberry attenuates whole-body insulin resistance in high fat-fed mice by reducing adipocyte death and its inflammatory sequelae. J Nutr. 2009;139:1510-6.

[22] Zhu Y, Ling W, Guo H, Song F, Ye Q, Zou T, et al. Anti-inflammatory effect of purified dietary anthocyanin in adults with hypercholesterolemia: A randomized controlled trial. Nutr Metab Cardiovasc Dis. 2013;23:843-9.

[23] Wallace TC. Anthocyanins in Cardiovascular Disease. Adv Nutr. 2011;2:1-7.

[24] Chuang CC, McIntosh MK. Potential mechanisms by which polyphenol-rich grapes prevent obesity-mediated inflammation and metabolic diseases. Annu Rev Nutr. 2011;31:155-76.

[25] Karlsen A, Retterstol L, Laake P, Paur I, Kjolsrud-Bohn S, Sandvik L, Blomhoff R. Anthocyanins inhibit nuclear factor-kB activation in monocytes and reduce plasma concentrations of pro-inflammatory mediators in healthy adults. J Nutr. 2007;137: 1951-4. 
[26] Seymour EM, Lewis SK, Urcuyo-Llanes DE, Tanone II, Kirakosyan A, Kaufman PB, Bolling SF. Regular tart cherry intake alters abdominal adiposity, adipose gene transcription, and inflammation in obesity-prone rats fed a high fat diet. J Med Food. 2009;12:935-42.

[27] Haddad JJ, Abdel-Karim NE. NF-кB cellular and molecular regulatory mechanisms and pathways: Therapeutic pattern or pseudoregulation? Cell Immunol. 2011;27:5-14.

[28] Li J, Yin Q, Wu H. Structural basis of signal transduction in the TNF receptor superfamily. Adv Immunol. 2013;119:135-53.

[29] Hoesel B, Schmid JA. The complexity of NF-кB signaling in inflammation and cancer. Mol Cancer. 2013;12:86.

[30] Oltman CL, Richou LL, Davidson EP, Coppey LJ, Lund DD, Yorek MA. Progression of coronary and mesenteric vascular dysfunction in Zucker obese and Zucker diabetic fatty rats. Am J Physiol Heart Circ Physiol. 2006;291(4):780-7.

[31] Subramanian R, MacLeod KM. Age-dependent changes in blood pressure and arterial reactivity in obese Zucker rats. Eur J Pharmacol. 2003;477(2):143-52.

[32] Andrews TJ, Laight DW, Anggård EE, Carrier, MJ. Investigation of endothelial hyperreactivity in the obese Zucker rat in-situ: Reversal by vitamin E. J Pharm Pharmacol. 2000;52(1):83-6.

[33] Moncada S, Higgs A. The L-arginine-nitric oxide pathway. N Engl J Med. 1993;329(27):2002-12.

[34] Mollace V, Muscoli C, Masini E, Cuzzocrea S, Salvemini D. Modulation of prostaglandin biosynthesis by nitric oxide and nitric oxide donors. Pharmacol Rev. 2005;57(2):217-52.

[35] Vanhoutte PM. Endothelial control of vasomotor function: From health to coronary disease. Circ J. 2003;67(7):572-5.

[36] Vendrame S, Daugherty A, Kristo AS, Klimis-Zacas D. Wild blueberry-enriched diet (Vaccinium angustifolium) improves dyslipidemia and modulates the expression of genes related to lipid metabolism in obese Zucker rats. Br J Nutr. 2014;111:194-200.

[37] Vendrame S, Zhao A, Merrow T, Klimis-Zacas D. The effects of wild blueberry consumption on glucose metabolism in the obese Zucker rat, a model of metabolic syndrome. J Med Food. 2015;18:619-24. 